\title{
Intraventricular Silicone Oil: An Imitator
}

\author{
${ }^{1}$ Ajit K Reddy, ${ }^{2}$ Manjunath Narayanappa, ${ }^{3}$ Anil K Shukla, ${ }^{4}$ Annitha E Jayamohan
}

\begin{abstract}
Introduction: Silicone oils are used in vitreoretinal surgery and it helps in maintaining the shape and fullness of the orbital globe. Rarely, they may get leaked from the orbit and may track to the brain in cerebrospinal fluid spaces like cisterns, ventricles. This can be documented by computed tomography with hyperdense oil. We are presenting a very rare case of the orbital silicon oil seepage into the ventricle.

We report the role of multidetector computed tomography to see silicone oil migrating from orbits to the brain. Not many cases are reported in the literature.
\end{abstract}

Keywords: Computed tomography, Retinal detachment, Silicon oil.

How to site this article: Reddy AK, Narayanappa M, Shukla AK, Jayamohan AE. Intraventricular Silicone Oil: An Imitator. J Med Sci 2016;2(3):48-49.

Source of support: Nil

Conflict of interest: None

\section{INTRODUCTION}

Silicone oils are important tools in vitreoretinal surgery and their introduction has represented a pivotal moment in the management of ophthalmic surgery as they are equipped with a combination of chemical and physical properties that have propelled their surgical use. They are essentially used as intraocular tamponade, thanks to their ability to maintain the adhesion between retina and retinal pigment epithelium. ${ }^{1}$

Silicone oil is commonly used in ophthalmology; however, it possesses few ocular complications. We here report one such case of a 56-year-old man who presented to us with generalized weakness. A plain computed tomography (CT) scan of the brain was done which showed silicon seepage from right orbit to left lateral ventricle. Past history revealed silicone oil being used

${ }^{1}$ Assistant Professor, ${ }^{2}$ Consultant, ${ }^{3}$ Professor, ${ }^{4}$ Senior Resident

${ }^{1,4}$ Department of Radiodiagnosis, Kempegowda Institute of Medical Sciences, Bengaluru, Karnataka, India

${ }^{2}$ Department of Radiology and Imaging, MediHope Super Specialty Hospital, Bengaluru, Karnataka, India

${ }^{3}$ Department of Radiodiagnosis, RajaRajeswari Medical College \& Hospital, Bengaluru, Karnataka, India

Corresponding Author: Anil K Shukla, Professor, Department of Radiodiagnosis. RajaRajeswari Medical College \& Hospital Bengaluru, Karnataka, India, Phone: +919342508923, e-mail: shookla2007@yahoo.co.in as a tamponade for retinal detachment. The migration of this silicon intracranially is rare and very few instances have been reported till date., ${ }^{2,3}$

\section{CASE REPORT}

A 56-year-old man presented to us with generalized weakness. Past history revealed silicone oil being used as a tamponade for retinal detachment. A CT scan of the orbit and the brain was done which showed silicon oil in nondependent portion of the left lateral ventricle.

\section{DISCUSSION}

Retinal detachment occurs when retinal pigment epithelial layer is separated from the sensory retina by fluid. It is classified into: (1) Rhegmatogenous, i.e., hole in sensory retina, (2) nonrhegmatogenic. Most are rhegmatogenic. Holes are secondary to retinal degeneration - on vitreous traction from liquefaction of vitreous. Spontaneous retinal detachment occurs in 10 persons per 100,000/ year. There are many predisposing factors, like high myopia, surgical aphakia (lens absence), and a history of retinal detachment of contralateral eye. It is not acute but gradual symptoms lead to vision loss. The treatment of retinal detachment is done by three methods: (1) Sleral buckle, (2) pars plana vitrectomy, and (3) some temporary tamponade with intraoccular silicon oil. Postoperative complications seen from 6 months to 5 years are cataract, silicon oil emulsification, keratopathy, glaucoma, pain, fibrous epiretinal and subretinal proliferations, and sub conjunctival deposits of oil, etc. A large series of 450 and 170 cases did not show this complication as we saw. ${ }^{4,5}$

First coined by FS Kipping in the year 1901 as "Siloxane" better known as Silicone, is an inert, synthetic compound with a multitude of forms and uses. Medical grade silicone in the gel form is used in bandages and dressings, breast implants, testicle implants, pectoral implants as well as contact lenses. ${ }^{1}$ Though, silicone is known to incite an inflammatory response in tissues, no threatening complications has been reported till date.

Silicone oil bears a relatively high attraction of molecules for each other. This property of silicone oil makes it a suitable agent for intravitreous tamponade in cases of retinal detachment. Migration of this silicon intracranially is rare and a very few instances have been reported till date. A plain CT scan of the orbit and the brain was done which showed bright hyperdense silicon oil in right orbital globe 
(Fig. 1). It has seeped through the optic nerve, chiasma and has crossed over to the left side and has reached frontal and temporal horns of the left lateral ventricle. Rest of the brain parenchyma was normal. No hydrocephalous or calcification was noted. The left orbit was normal (Figs 2A and B).

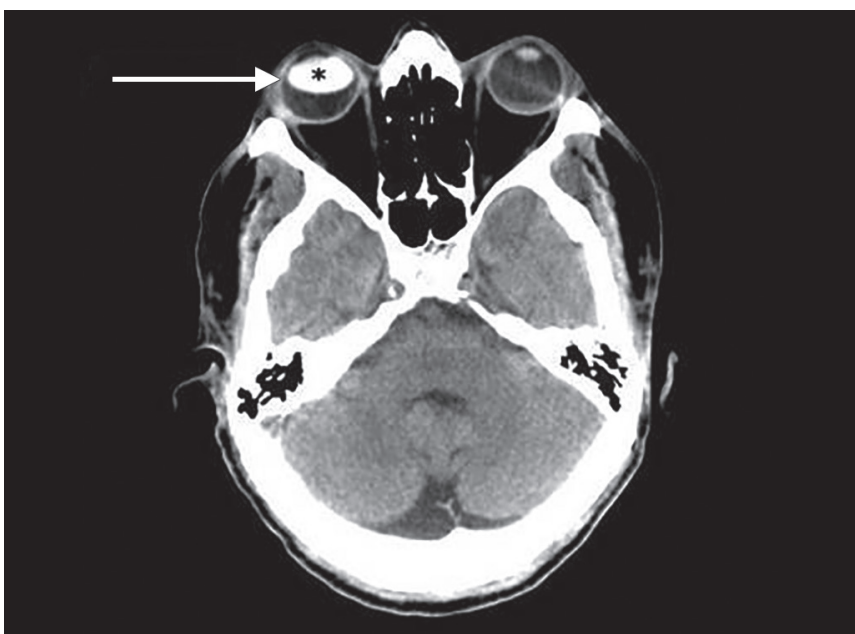

Fig. 1: Noncontrast-enhanced brain CT image demonstrating silicone oil in the right eye (Arrow)
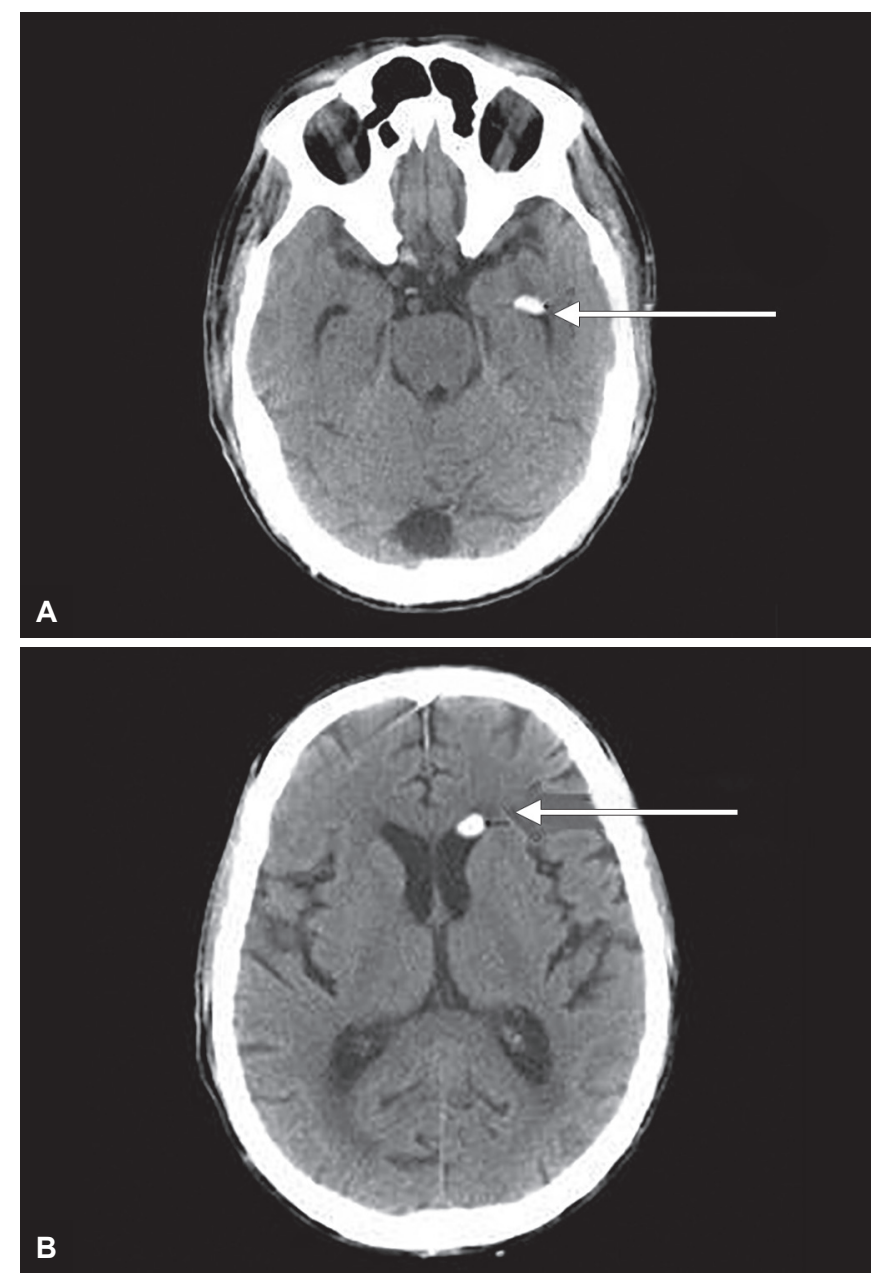

Figs 2A and B: Noncontrast-enhanced brain CT obtained with the patient in the supine position. Silicone oil seen floating in the nondependent portion of the frontal and temporal horn of the left lateral ventricle (Arrows)
Intraventricular extension is hypothesized to be through the silicone oil-filled spaces in the optic nerve. ${ }^{2}$ The intraventricular nodules were found to freely float and stay in nondependent parts of the ventricles even when the patient's position changed from supine to prone. ${ }^{3}$

The key differentiating points include a well-defined, more or less rounded configuration of the silicone oil (due to its higher surface tension) as compared to a fluid-fluid configuration of the intraventricular hemorrhage. Secondly, the silicone oil, due to its low specific gravity tends to occupy a nondependent position. Lastly, the attenuation value of the intraventricular silicone oil closely parallels that used for the intravitreous silicon tamponade.

Silicone oils are very useful surgical tools because they are able to simplify the surgical management of many vitreoretinal diseases. With the modern vitrectomy systems and the possibility to use such different tamponades, the prognosis of several diseases has improved. According to the vitreoretinal pathology, we can choose between varieties of options.

We are not aware whether silicon is depositing in neural tissues. This is designed to remain in the orbit and not deposit in tissues. It is too early to determine the significance of the study results as we do not know any health risks at this time. It is important to note that the pathologists investigating the brain tissue with the silicon deposits may find some changes or neural tissue damage.

\section{CONCLUSION}

Silicon in orbit for treatment and cosmetic reasons is good; however any complications like leakage into the brain is rare. We have to further understand long-term effects in brain and also its migration to thecal sac to nerve roots to outside in follow-ups. We recommend use of multidetector computed tomography in follow-up of cases of intraocular silicon implant.

\section{REFERENCES}

1. Wikipedia. Silicone. [Internet] [cited 2016 February 20]. Available from: http://en.wikipedia.org/wiki/Silicone.

2. Campbell G, Milbourne S, Salman U, Khan M. Ocular silicone oil in the lateral cerebral ventricle. J Clin Neurosci 2013 Sep;20(9):1312-1313.

3. Chang $\mathrm{C}$, Chang $\mathrm{H}$, Toh $\mathrm{C}$. Intraventricular silicone oil. J Neurosurg 2013 May;118(5):1127-1129.

4. Riedel KG, Gabel VP, Neubauer L, Kampik A, Lund OE. Intravitreal silicone oil injection: complications and treatment of 415 consecutive patients. Graefes Arch Clin Ecp Ophthalmol 1990;228(1):19-23.

5. Federman JL, Schubert HD. Complications associated with the use of silicone oil in 150 eyes after retina-vitreous surgery. Ophthalmology 1988 Jul;95(7):870-876. 